\title{
Constraining the activity of the North Atlantic Igneous Province across the Paleocene-Eocene boundary
}

MORGAN T. JONES ${ }^{1}$, Ella W. STOKKE ${ }^{1}$, LARS E. Augland ${ }^{1}$, Henrik H. SVENSEN ${ }^{1}$ PHILIP A.E. PogGe VON STRANDMANN ${ }^{2}$, ALAN D. ROONEY ${ }^{3}$

${ }^{1}$ Centre for Earth Evolution and Dynamics (CEED), University of Oslo, Norway.

(*Correspondence: m.t.jones@geo.uio.no)

${ }^{2}$ London Geochemistry and Isotope Centre (LOGIC), Institute of Earth and Planetary Sciences, University College London and Birkbeck, University of London, UK. ${ }^{3}$ Department of Geology and Geophysics, Yale University, New Haven, Conneticut, USA.

The close temporal correlation between the main phase of North Atlantic Igneous Province (NAIP) volcanism and the Paleocene-Eocene Thermal Maximum (PETM) at $\sim 56 \mathrm{Ma}$ suggests a potential causal connection. Volcanic activity was prevalent across this boundary, but current radioisotopic ages are too low-resolution to accurately assess any potential climate forcing. An ideal locality for assessing various volcanic and climatic proxies in unison is the island of Fur, northwest Denmark. The sedimentary sequence consists of clays and diatomites containing hundreds of tephra layers that were deposited in an epicontinental, shallow marine sea. The high sedimentation rates and close proximity to the NAIP means there are numerous proxies that can be used to provide high-resolution records, constraining the relative and absolute timings of volcanic activity and climate variability in a single section.

Here we present the findings of the project 'Ashlantic', which implemented a multiproxy approach to Fur strata. Volcanic tracers such as tephra horizons and $\mathrm{Hg}$ anomalies are used to infer the timing, intensity, and style of NAIP activity. Detailed chemostratigraphic logs and datasets (e.g. $\delta^{13} \mathrm{C}$ ) define the onset and duration of the PETM. Weathering intensities are constrained with clay fractions and $\mathrm{Li}$ and $\mathrm{Os}$ isotopes, which track the climatic response to the PETM global warming. Precise U-Pb dating of ash layers provides further constrains on the timing of NAIP activity and the duration of the PETM.

These results indicate that the NAIP was very active just before and after the PETM, but the relationship between volcanism and the body of the PETM is inconclusive. These findings call for further work, such as new ICDP and/or IODP drilling of North Sea sediments to improve site coverage proximal to the NAIP. 